\title{
cMaJPPEN
}

\section{Women's postpartum experiences in Canada during the COVID-19 pandemic: a qualitative study}

\author{
Kathleen Rice PhD, Sarah Williams PhD
}

\section{Abstract}

Background: The mental health of postpartum women has worsened during the COVID-19 pandemic; however, the experiences that underlie this remain unexplored. The purpose of this study was to examine how people in Canada who gave birth during the pandemic were affected by policies aimed at limiting interpersonal contact to reduce SARS-CoV-2 transmission in hospital and during the early weeks postpartum.

Methods: We took a social constructionist approach and used a qualitative descriptive methodology. Sampling methods were purposive and involved a mix of convenience and snowball sampling via social media and email. Study inclusion was extended to anyone aged 18 years or more who was located in Canada and was pregnant or had given birth during the COVID-19 pandemic. Data were obtained via semistructured qualitative telephone interviews conducted between June 2020 and January 2021, and were analyzed through thematic analysis.

Results: Sixty-five interviews were conducted; data from 57 women who had already delivered were included in our analysis. We identified the following 4 themes: negative postpartum experience in hospital owing to the absence of a support person(s); poor postpartum mental health, especially in women with preexisting mental health conditions and those who had had medically complicated deliveries; asking for help despite public health regulations that prohibited doing so; and problems with breastfeeding owing to limited in-person follow-up care and lack of in-person breastfeeding support.

Interpretation: Policies that restrict the presence of support persons in hospital and at home during the postpartum period appear to be causing harm. Measures to mitigate the consequences of these policies could include encouraging pregnant people to plan for additional postpartum support, allowing a support person to remain for the entire hospital stay and offering additional breastfeeding support.

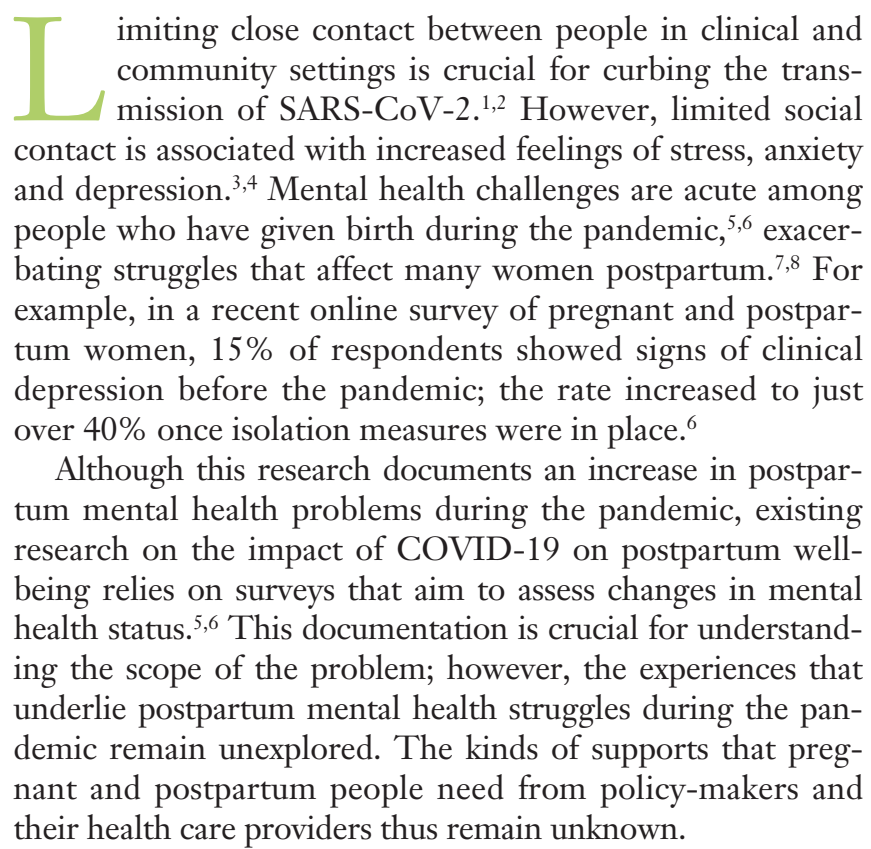

To address this gap, we drew on qualitative interviews conducted across Canada to examine how people in Canada have been affected by policies aimed at limiting interpersonal contact to reduce SARS-CoV-2 transmission while giving birth in hospital and during the first weeks postpartum.

\section{Methods}

\section{Study design}

This qualitative study took a social constructivist approach, ${ }^{9}$ meaning the knowledge that informed and was produced through this research was socially constructed by people through their interactions with others. Central to this

\section{Competing interests: None declared.}

This article has been peer reviewed.

Correspondence to: Kathleen Rice, Kathleen.rice@mcgill.ca CMAJ Open 2021. DOI:10.9778/cmajo.20210008 
research paradigm is the assumption that knowledge should be gained from people who have lived the phenomenon that is under investigation, knowing that multiple perspectives may coexist within the study" (e.g., a "good birth" may mean different things to different people).

The study was guided by a qualitative descriptive methodology, a form of qualitative research that aims to remain close to the data (for instance, by using participants' own language) to gain rich, descriptive insights via participants' narratives of their experiences. ${ }^{10,11}$ This approach produces findings that are clear and straightforward, and is thus ideal for research areas where much is unknown but where recommendations for clinical practice are needed..$^{10,11}$

In this paper, we focus on data related to consequences of policies aimed at reducing interpersonal contact during the early postpartum period and with actionable implications for clinical practice. Other results from this large data set are beyond the scope of this paper (unpublished data, 2020).

\section{Sampling and recruitment}

Sampling methods were purposive and involved a mix of convenience and snowball sampling. ${ }^{12}$ A recruitment email was posted and made "sharable" on social media (K.R.'s personal Facebook account and her professional Twitter account) in June 2020. Interested participants from across Canada contacted K.R. via email or Facebook Messenger. Study inclusion was extended to anyone located anywhere in Canada who was pregnant or had given birth during the COVID-19 pandemic, provided they were 18 years of age or more. Recruitment materials did not specify a time frame for study inclusion; participants themselves determined whether their pregnancy and birth had occurred during the pandemic. All recruitment materials were deliberately gender inclusive - that is, worded to recruit "pregnant people and those who had recently given birth" rather than "pregnant women and new mothers."

\section{Data sources}

The interview guide (Appendix 1, available at www.cmajopen. ca/content/9/2/E556/suppl/DC1) was developed by K.R. through consultation with literature on pregnancy, birth, mental health and pandemics. ${ }^{13-16}$ It was pilot tested once with an interviewee who is a researcher in the areas of gender and health, and was pregnant and located in Canada at the time of interview. The data from this pilot interview were included in the study. The interview guide was subsequently refined in alignment with her expert feedback.

Semistructured telephone interviews were conducted between June 2020 and January 2021 by K.R., a medical anthropologist with extensive experience in qualitative interviewing and a mother. In addition to narrative responses to the interview questions, basic demographic data (age, number of viable pregnancies, geographic location, identification as a member of a minority group) were collected verbally. Additional information (site and mode of delivery, profession of health care provider [e.g., obstetrician, midwife], size of community according to Statistics Canada criteria ${ }^{17}$ ) were extracted from the interview narratives after the interview. All participants signed an informed consent form digitally before the interview.

Interviews were digitally recorded, transcribed verbatim, anonymized and verified by K.R. Transcription was done by a professional transcription service bound by a confidentiality agreement approved by the McGill Institutional Review Board, and files were shared via secure server.

During the interviews, K.R. produced "scratch notes"18 brief documentation of her personal reflections on interviewees' narratives and their potential connection to the broader data set; observations about tone, emotion or accent that are often missed in transcripts; relevant background noise (e.g., a baby crying); and reminders of prompts for follow-up questioning. After the interviews, these scratch notes were written up into field notes.

Transcripts were not returned to participants for review; all participants were busy parenting newborns during a pandemic and lacked time for transcript review.

\section{Data analysis}

We analyzed the data using thematic analysis, ${ }^{19,20}$ a flexible approach that is especially suited to summarizing meaningful features of large descriptive qualitative data sets. First, each transcript was read independently by both authors for the purposes of data familiarization, ${ }^{19}$ and each made informal notes about apparent patterns and meanings. Then, we used a coding approach that involved both authors' independently interpreting and labelling sections of data according to highly specific characteristics (e.g., "crying a lot"). ${ }^{21,22}$ Once 10 transcripts had been coded in this way, we compared interpretations, collaborated on grouping codes according to similar meanings and developed shared definitions of codes. The remainder of the data was then systematically interpreted according to these agreed-upon definitions, with occasional modifications made to the codes as our interpretations evolved through the analysis of additional data.

As this process progressed, it became possible to apply greater analytic judgment about the meaning of the data, allowing for the construction of broader "themes" (e.g., "poor postpartum mental health") by bringing together similar ideas and experiences from across the data set. Although described in a stepwise manner for ease of explanation, developing codes and themes entails constant back and forth between raw data and interpretations.

Within the social constructionist research paradigm, the researcher's own perspective is integral to and inseparable from the analytic process described above. In this case, our interpretation was shaped, for instance, by our personal identities (as cis-gendered White women) and disciplinary expertise (as medical anthropologists trained in critical analysis of biomedical health care as a cultural system). Although objectivity is not the goal of this kind of research, we nevertheless took steps to ensure that our interpretations were as informed and unbiased as possible. Specifically, we included input from peers, including clinician colleagues, by sharing our data and interpretations through informal debriefs, and formal seminar and conference presentations. We reworked the coding 
framework in response to this feedback. ${ }^{20}$ We also actively reflected on how our identities and perspectives shaped our analysis ("reflexivity"), ${ }^{23}$ and, at all stages, we wrote memos and journalled to create an audit trail of the decisions that shaped the analysis; we revisited this audit trail regularly to confirm the cogency of analytic decisions. ${ }^{24}$ We used NVivo 12 (QSR International) for data management.

\section{Ethics approval}

We obtained ethics approval for this study from the McGill University Faculty of Medicine Institutional Review Board.

\section{Results}

Sixty-five interviews were collected, ranging from 25 to 75 minutes in length. Although repetition of key topics was apparent after about 30 interviews, we conducted an additional 35 interviews to ensure a broader representation in terms of location, age and ethnicity. All respondents were cisgendered women. Participant demographic characteristics, mode of delivery, date and place of birth, perinatal care provider and location are provided in Table 1 . Of the 65 participants, 8 had not yet given birth; their data were not included in the analysis. No participant refused to participate or withdrew from the study.

We developed 4 themes that follow from policies aimed at reducing interpersonal contact during the early postpartum period and that have actionable implications for clinical practice: negative postpartum experience in hospital, poor postpartum mental health, asking for help and breastfeeding problems.

\section{Negative postpartum experience in hospital}

A few participants felt that the pandemic had little impact on their hospital stay. These women were generally second- or third-time mothers without preexisting mental health conditions whose pregnancies and births had been free of medical complications. Although some were affected by policies that required their birth partners to leave the hospital shortly after delivery, these women needed limited in-hospital support postpartum and welcomed the opportunity for undisturbed rest with their newborns. This experience is exemplified by the first quote in Box 1.

However, for women whose deliveries entailed medical intervention, the lack of postpartum support in hospital resulted in suffering. For example, the second quote in Box 1 provides the experience of a woman whose husband was required to leave shortly after she gave birth via emergency cesarean delivery, leaving her alone, and the third quote conveys the experience of a woman who was hard of hearing and had long-standing clinically diagnosed struggles with anxiety; her husband was required to leave the hospital 4 hours after she gave birth to her second child by scheduled cesarean delivery.

Several interviewees had babies that required intensive care postpartum. For example, the fourth quote in Box 1 provides the experience of a woman who had medical complications after an emergency cesarean delivery and was discharged the

\section{Table 1: Demographic characteristics of participants}

\begin{tabular}{|lc|}
\hline Characteristic & $\begin{array}{c}\text { No. (\%) of participants* } \\
n=65\end{array}$ \\
\hline Age range, yr & $22-43$ \\
\hline Age, mean, yr & 34 \\
\hline Ethnic or gender minority & $12(18)$ \\
\hline \multicolumn{1}{|c|}{ Indigenous } & $2(3)$
\end{tabular}

Birth date range Mar. 19, 2020-Jan. 4,

2021

No. of viable pregnancies $†$

\begin{tabular}{|cc|}
\hline 1 & $31(48)$ \\
\hline 2 & $24(37)$ \\
\hline 5 & $8(12)$ \\
\hline Twin pregnancy & $2(3)$ \\
\hline Birth location & $4(6)$ \\
\hline
\end{tabular}

Birth location

Academic hospital $26(40)$

Community hospital 22 (34)

Hospital, type unknown 5 (8)

Home $3(5)$

Birthing centre $1(2)$

Not yet given birth 8 (12)

Perinatal care provider

Obstetrician $42(65)$

Family physician $12(18)$

Midwife 11 (17)

Mode of delivery

Vaginal $39(60)$

Emergency cesarean birth 10 (15)

Scheduled cesarean birth 8 (12)

Not yet given birth 8 (12)

Province/territory

Ontario 25 (38)

Newfoundland and Labrador $\quad 14(22)$

British Columbia $10(15)$

Quebec $4(6)$

Northwest Territories $\quad 4(6)$

New Brunswick 3 (5)

Manitoba 2 (3)

Nova Scotia 2 (3)

Alberta 1 (2)

Community size (population) $)^{17}$

\begin{tabular}{lc|}
\hline Large $(\geq 100000)$ & $43(66)$ \\
\hline Medium (30 000-99 999) & $6(9)$ \\
\hline Small (1000-29 999) & $15(23)$ \\
\hline Remote $(<1000)$ & $1(2)$ \\
\hline $\begin{array}{l}\text { Except where noted otherwise. } \\
\text { Includes current pregnancy. }\end{array}$
\end{tabular}




\section{Box 1: Postpartum experience in hospital}

\section{Positive}

Looking back, it was nice to not have any visitors and just be with the baby. I think that was something that a lot of people didn't really consider when they found out that they weren't allowed to have any visitors. I don't think people really realized the benefit of just having that alone time with the baby. (Interview 20)

\section{Negative}

I had lost a significant amount of blood during my [cesarean delivery]. My hemoglobin dropped down to 74 [g/L], and they usually give you a blood transfusion at $70[\mathrm{~g} / \mathrm{L}]$. And I wasn't putting out enough urine so they kept the catheter in me, so when they took the catheter out, I couldn't pee. My bladder became incredibly distended, and it was the worst pain I had ever felt in my entire life. They had one of those little hats on the toilet where they wanted to measure my urine output, and I just kept flooding it, and flooding it, and flooding it, and finally I was just sitting there in my own urine because I couldn't get up [because of] the pain from the [cesarean delivery], the [hip] pain from [carrying the baby]. ... I was just a total wreck sitting there. (Interview 12)

I didn't cope [with the lack of support person] very well. The second night was horrific. I cried pretty much the entire night. I was trying to breastfeed but it wasn't working, so after the second night, I basically decided to formula feed [the baby]. And you can't even really see anyone's faces because they were all wearing masks. You didn't really know ... who you were talking to. My problem was I couldn't hear what they were saying because I couldn't lip read. (Interview 19)

I was using a wheelchair to move around because the NICU is up several floors. We would try and sneak [my husband] in to just wheel me to the place, but then a nurse recognized us, and we got yelled at and he had to leave, and so I had to start walking to the NICU by myself. Again, this is days after the surgery, to go on these huge walks up to the fourth floor ... I was just breaking. Then I had to go sit in this crazy uncomfortable chair with the baby, and it was just really hard physically, by myself, to do all this stuff. At first the nurses were helping, and then the policy changed and they were no longer allowed to come near me. I'm like, "I need help, I need help with all of these wires, my baby is attached to 7000 wires. I can barely move, the baby is nursing, my water is over there," and no one could help me. We [postpartum women] were reprimanded. Instead of [the nurses'] just being understanding, we were being yelled at. We were like, "Don't you understand?! I just had a surgery, and my baby is sick." ... I was pretty depressed. I would cry every day, I was so upset. (Interview 25)

[My partner] had to leave 4 hours after [I delivered]. It was terrifying. l'd never had a baby before, and I had the whole night and then the whole next day to take care of a newborn by myself after having a hard labour and delivery. I was there alone, I was on pain medication. It was not set up to help women at all. It was more helpful for the staff than it was for the parent. I felt - not by [my partner], but by our health care system during this time ... - abandoned and forgotten about. (Interview 7)

I was so sick, I needed help. I needed someone to walk me to the bathroom, and I needed help getting out of bed. At the time, your support person was only allowed to be with you for 4 hours after your child was born. So ... that was incredibly, incredibly hard being in the hospital by yourself, especially not feeling well and with a new baby. I almost felt like I was in jail, honestly, at times. (Interview 27)

Directly after the birth, when my husband had to leave the hospital and I had to stay in for a whole day and night without him, that was probably one of the hardest days of my life. I felt really alone. I didn't know if I was going to get through it. And I had a second-degree tear, and I was trying to breastfeed and all that ... just doing that alone was really traumatic, to be honest. There [were] a couple of times where I just really felt like I was at my breaking point because my daughter was crying so much and I just didn't know what to do. (Interview 34)

Note: $\mathrm{NICU}=$ neonatal intensive care unit. next day. Her baby also experienced complications and required intensive care for 1 week. This participant's narrative conveys the challenges of trying to care for a baby and establish breastfeeding at a time when hospital policy prohibited more than 1 visitor.

\section{Poor postpartum mental health}

Interviewees' narratives suggest that having a newborn at home during the pandemic was challenging for most women (Box 2), and these challenges were compounded by lack of support. This was amplified for those with preexisting mental health conditions and those recovering from difficult births. For example, the first 2 quotes in Box 2 convey the experience of new motherhood during the pandemic for some women with preexisting mental health conditions.

\section{Asking for help}

As illustrated in the second quote in Box 2, we found that many interviewees eventually did allow support persons into the home. This speaks to a third theme that was common across many interviews: seeking out help even where public health policies did not permit it (Box 3). For most interviewees, this decision was accompanied by stress about the risks associated with close contact and was usually done only when the mother had become desperate.

\section{Breastfeeding problems}

Lack of support in hospital and at home influenced some women to stop breastfeeding sooner than they had wished to (Box 4). Online breastfeeding supports were uniformly experienced as unhelpful.

\section{Interpretation}

This study shows that COVID-19 pandemic policies that restrict the presence of support persons both in hospital and at home during the postpartum period had negative consequences for women who gave birth in Canada. Although some women coped well and valued the opportunity for uninterrupted time with their newborns, for those with preexisting mental health conditions, those whose deliveries entailed medical complications and those who struggled to breastfeed successfully without support, pandemic-related policies exacerbated their preexisting struggles.

There are several ways in which our participants' experiences can inform better postnatal care during the pandemic. First, our findings show that the challenges posed by postpartum mental health struggles and recovery from complicated births are intensified by pandemic-related policies that separate people from the supports that they need after delivery. This is particularly concerning given that mental health struggles are widespread in Canada, including among 


\section{Box 2: Poor postpartum mental health}

I think I had a bit of postpartum depression. I do have some anxiety as well ... even before pregnancy. So, the first 2 or 3 weeks I felt like I was going crazy. I felt like I was going insane because I was so ill, I couldn't stay awake for long, I was really weak. My incision wasn't healing properly. At this time, my boyfriend was trying to work from home, and he wasn't sleeping and I wasn't sleeping. I couldn't reach out for help from my mom. She couldn't even come over to my house to help me out. So that was super hard for us. It was hard not being able to reach out and have the family there when you needed them the most.

(Interview 17)

I have depression and anxiety, for which I am on Prozac and I have a therapist. And, thankfully, they are both fine and under control, but it was really, really difficult for the first few weeks being home and isolated and being afraid of catching COVID. And knowing that our baby doesn't have an immune system, we don't want to jeopardize his health or his life by letting people into our house, so we were in essentially full quarantine, and that was really difficult for me. And I know that a lot of the hormonal swings are very normal, but there wasn't that support for when you're crying and exhausted. My mom wasn't there to hand the baby over to so that I could take a nap. After [my husband] went back to work, it was very difficult, physically and emotionally. And I found that, by week 6 , I was crying a lot, the baby was crying, I was crying and exhausted, and really feeling the guilt of feeling like I needed help and not wanting to risk our family. How much struggle to endure for their safety versus knowing that our mental health would be so much better if we let one of our parents into the house? And that wound up being the decision that we made with my therapist because it was the simple solution. I needed my mom. (Interview 9)

I know [that] a lot of women who gave birth around the same time as me, or during when the restrictions were at the heaviest, they suffered from postpartum depression. I know that I suffered big time from baby blues, and I thought, "For sure, I'm going to need to be medicated after this, $100 \%$." When I got home, I think I cried for 2 weeks straight. (Interview 7)

The isolation was really hard for me. When I look at what has happened in the last 6 months, I had a baby, I was locked in my house, I couldn't see my mom, I couldn't see my grandmother, who's dying. And here I was trying to just pretend that everything was normal for a 5-year-old so that he's not scared. Yes, it was a hard few months, thinking about it all like that. (Interview 33)

pregnant women, ${ }^{8}$ and that many births entail complications. ${ }^{25}$ Furthermore, despite feelings of stress and guilt, some postpartum women, of necessity, let people into their households to provide needed support; most reported doing so only when they had reached a point where they were no longer able to safely care for themselves and their babies. Not only is it dangerous to reach a state of desperation before seeking help, it also means that the person who is invited into the home is someone who is immediately available — often an older parent, who is more vulnerable than others to hospital admission or death from COVID-19.

Accordingly, we believe that a practical and realistic approach to supporting pregnant people is needed during the pandemic, especially for people with preexisting mental health conditions and those who have medically complicated births.

\section{Box 3: Asking for help}

The isolation and not being able to have any help from your family or friends - I think that was the toughest part. You kind of get squirrelly and start losing your mind a little. So, at 7 weeks, we just pulled the plug. I was video-chatting with my sister and she [said], "You know, there's a balance between what's going on and mental health, too. Maybe we need to start having these conversations." But my mom lives with her parents, who are in their 90s, and my sister's husband has a compromised immune system, so there was a lot of, "What do we do?" (Interview 13)

At some point, you have to look at what's more important, your mental health or a risk, which [in our community] was so low. ... Are you sacrificing your mental health, which is, in my mind, just as serious as COVID? That's how we started to feel toward the end. ... The mental health thing was a big factor [in our decision to let someone in], for sure. (Interview 33)

I hemmed and hawed and was very stressed over [letting my dad in to help], because I knew it was opening up to a whole other household. My dad was even popping in and out of work then still, so I did know it was a bigger bubble than what we were allowed. But I also knew that I didn't really have a choice. I just did what worked for my family and me at the time. (Interview 43)

Many people clearly need at least 1 support person to remain with them for their entire hospital stay after birth, and many will open up their household for the sake of their mental health and child's safety regardless of public health policies. A realistic approach might entail encouraging pregnant women to plan for additional postpartum support and coaching them ahead of time on how to both choose a suitable person (for instance, a sibling rather than a parent) and plan ahead so that their support person can join the postpartum person's household safely; and allowing at least 1 support person to remain with the postpartum person for the entire hospital stay.

Moreover, the right to dignity, respect and support in the early postpartum period is codified in guidelines established by the Canadian federal government. ${ }^{26}$ Prepandemic scholarly studies and journalist investigations in Canada showed that these rights are not always upheld, ${ }^{27,28}$ particularly for Indigenous and racialized women. ${ }^{29,30}$ The experiences of some participants in the current study indicate that pandemic-induced policies in maternal health care institutions have continued and even deepened these patterns. Sitting in their own urine while in pain, crying alone for hours, being yelled at while trying to care for a sick newborn just days after abdominal surgery; this is harsh and undignified treatment, and this study shows that these are unintended outcomes of policies that limit the presence of a support person during the postpartum period. It is important to note that these findings echo what has been recognized for decades as a common result of the policy of evacuation of Indigenous women from northern communities for childbirth - isolation from family and community, increased risk of mistreatment and racism owing to lack of support persons, and negative impacts on mental health and breastfeeding. ${ }^{31,32}$ Although the extreme examples above are rarely the experiences of people with uncomplicated vaginal deliveries, they are also the price that those who have 


\section{Box 4: Breastfeeding problems}

[After] we came back [from hospital] ... I continued to have trouble breastfeeding. I couldn't get help from a lactation consultant ... because, of course, they weren't doing in-home visits. [I] couldn't get help from family or friends who had [breastfed] before because, of course, we weren't able to see anyone. It was hugely challenging. We eventually ... just started to pump exclusively, and ... that had its own host of issues. I wish I had had more inperson support for that part, for sure. ... That was $100 \%$ worse than birth the first couple of weeks. (Interview 41)

I had a couple of virtual appointments [with lactation consultants], which I found totally useless. I was so desperate to make it work because I had such a wonderful experience nursing my first kid and I was ... devastated that it wasn't working with [the new baby] because it was something I was really looking forward to. (Interview 32)

I've noticed a lot of people are quitting breastfeeding [because of] lack of support during the pandemic. ... I tried [to breastfeed] for a couple of weeks, but I couldn't get a lactation consultant, or I never had a visit from Public Health, or they're in the city. When you go to the [breastfeeding] clinics, maybe you realize, "Oh, wow, everybody has pain when they first start to nurse" or "Everybody feels this way!" But when you're a first-time mom, home, with people technically not allowed to visit... (Interview 18)

had complicated births are being asked to pay for the sake of minimizing traffic into and out of hospitals during the pandemic.

Finally, our data indicate that lack of support was a factor in many women's inability to breastfeed successfully. Although some were able to access online supports, these were uniformly viewed as ineffective. Given the benefits of breastfeeding, as upheld by the Canadian Paediatric Society, ${ }^{33}$ additional in-person breastfeeding supports should be provided to postpartum people within the constraints of what is safe during the pandemic.

\section{Limitations}

As with all qualitative research, the results of this study are not necessarily generalizable. Moreover, the overrepresentation of residents of Newfoundland and Labrador may have skewed findings in the direction of postpartum care issues specific to that province. However, similarities across 57 narratives from 8 provinces and 1 territory suggest that the experiences documented here are widespread across Canada.

Most of the interviews were collected before it was known that pregnant people are at increased risk for hospital admission and death in the event of COVID-19. ${ }^{34}$ This knowledge likely affects more recent experiences of pregnancy during the pandemic, as well as decisions about pregnancy care. Recruitment via social media may have excluded those with limited Internet access.

\section{Conclusion}

Our findings show that policies aimed at limiting interpersonal contact to reduce SARS-CoV-2 transmission have negative consequences for many women during the early postpartum period, especially with respect to mental health, breastfeeding success, and well-being and safety while in hospital. Interpreting the narratives of women who gave birth in Canada during the pandemic allows us to make evidencebased suggestions for how health care providers, administrators and policy-makers can provide care to pregnant and postpartum people that is pragmatic, ethical and compassionate during the pandemic. These might include allowing postpartum people to have close contact with chosen support persons after birth and coaching them on how to choose suitable support; allowing a support person to remain with the postpartum person for the entire hospital stay; and providing inperson breastfeeding supports.

\section{References}

1. Coronavirus disease (COVID-19): prevention and risks. Ottawa: Public Health Agency of Canada; modified 2021 Mar. 22. Available: www.canada.ca/en/ public-health/services/diseases/2019-novel-coronavirus-infection/prevention-risks. html (accessed 2020 Nov. 5).

2. Coronavirus disease (COVID-19) advice for the public. Geneva: World Health Organization; updated 2021 Mar. 26. Available: www.who.int/emergencies/ diseases/novel-coronavirus-2019/advice-for-public (accessed 2020 Nov. 5).

3. Carvalho Aguiar Melo M, de Sousa Soares D. Impact of social distancing on mental health during the COVID-19 pandemic: an urgent discussion. Int $\mathcal{F}$ Soc Psychiatry 2020;66:625-6.

4. Marroquín B, Vine V, Morgan R. Mental health during the COVID-19 pandemic: effects of stay-at-home policies, social distancing behavior, and social resources. Psychiatry Res 2020;293:113419.

5. Cameron EE, Joyce KM, Delaquis CP, et al. Maternal psychological distress \& mental health service use during the COVID-19 pandemic. 7 Affect Disord 2020;276:765-74.

6. Davenport MH, Meyer S, Meah VL, et al. Moms are not OK: COVID-19 and maternal mental health. Front Glob Womens Health 2020;1:1. doi: 10.3389/ fgwh.2020.00001.

7. Pregnancy and women's mental health in Canada: results from the Canadian Maternity Experiences Survey. Ottawa: Public Health Agency of Canada; 2014, modified 2016 May 17. Available: www.canada.ca/en/public-health/ services/publications/healthy-living/pregnancy-women-mental-health-canada. html (accessed 2020 Nov. 11).

8. "Psychology works" factsheet: post-partum depression. Ottawa: Canadian Psychological Association; 2015. Available: https://cpa.ca/docs/File/Publications/ FactSheets/PsychologyWorksFactSheet_Post-PartumDepression.pdf (accessed 2020 Nov. 11).

9. Mertens DM. Research and evaluation in education and psychology: integrating diversity with quantitative, qualitative, and mixed methods. 4th ed. Thousand Oaks (CA): Sage Publications; 2014.

10. Neergaard MA, Olesen F, Andersen RS, et al. Qualitative description - The poor cousin of health research? BMC Med Res Methodol 2009;9:52.

11. Kim H, Sefcik JS, Bradway C. Characteristics of qualitative descriptive studies: a systematic review. Res Nurs Health 2017;40:23-42.

12. Patton MQ. Qualitative evaluation and research methods. 2 nd ed. Thousand Oaks (CA): Sage Publications; 1990.

13. Lebel C, MacKinnon A, Bagshawe $M$, et al. Elevated depression and anxiety symptoms among pregnant individuals during the COVID-19 pandemic. $\mathcal{F}$ Affect Disord 2020;277:5-13.

14. Lohm D, Flowers P, Stephenson N, et al. Biography, pandemic time and risk: pregnant women reflecting on their experiences of the 2009 influenza pandemic. Health (London) 2014;18:493-508.

15. Lee DTS, Sahota D, Leung TN, et al. Psychological responses of pregnant women to an infectious outbreak: a case-control study of the 2003 SARS outbreak in Hong Kong. 7 Psychosom Res 2006;61:707-13.

16. McCourt C. Social support and childbirth. In: Squire C, editor. The social context of birth. London (UK): Routledge; 2017:191-214.

17. Population centre and rural area classification 2016. Ottawa: Statistics Canada; modified 2017 Feb. 8. Available: www.statcan.gc.ca/eng/subjects/standard/ pcrac/2016/introduction (accessed 2020 Nov. 16).

18. Arora AB, Bubp RL. Scratch notes. In: The international encyclopedia of communication research methods. Hoboken (NJ): John Wiley \& Sons; 2017:1-2.

19. Clarke V, Braun V. Thematic analysis. 7 Posit Psychol 2017;12:297-8.

20. Nowell LS, Norris JM, White DE, et al. Thematic analysis: striving to meet the trustworthiness criteria. Int 7 Qual Methods 2017;16. doi: 10.1177/ 1609406917733847

21. King N. Using templates in the thematic analysis of text. In: Cassell C, Symon $\mathrm{G}$, editors. Essential guide to qualitative methods in organizational research. London (UK): Sage Books; 2004:257-70.

22. Crabtree BF, Miller WL. Using codes and code manuals: a template for organizing style of interpretation. In: Crabtree B, Miller W, editors. Doing qualitative research. 2nd ed. Thousand Oaks (CA): Sage Publications; 1999:163-77. 
23. Finlay L. "Outing" the researcher: the provenance, process, and practice of reflexivity. Qual Health Res 2002;12:531-45.

24. Halpren ES. Auditing naturalistic inquiries: the development and application of a model [dissertation]. Bloomington (IN): Indiana University; 1983.

25. Labour and birth in Canada: infographic. Ottawa: Public Health Canada; 2018, modified 2020 Jan. 8. Available: www.canada.ca/en/public-health/services/ publications/healthy-living/labour-birth-infographic.html (accessed 2020 Nov. 16).

26. Care during labour and birth. In: Family-centred maternity and newborn care: national guidelines. Ottawa: Public Health Agency of Canada; 2018, modified 2020 Jan. 8. Cat no HP15-30/4-2018E-PDF. Available: www.canada.ca/en/ public-health/services/publications/healthy-living/maternity-newborn-care -guidelines-chapter-4.html (accessed 2020 Dec. 1).

27. Morton CH, Henley MM, Seacrist M, et al. Bearing witness: United States and Canadian maternity support workers' observations of disrespectful care in childbirth. Birth 2018;45:263-74.

28. Burns-Pieper A. Stop! Stop!': Canadian women share stories of alleged mistreatment in the delivery room. CBC News 2016 Nov. 7. Available: www.cbc. ca/news/health/child-birth-mistreatment-complaints-1.3834997 (accessed 2021 Mar. 12).

29. Vedam S, Stoll K, McRae DN, et al. Patient-led decision making: measuring autonomy and respect in Canadian maternity care. Patient Educ Couns 2019; 102:586-94.

30. Kolahdooz F, Launier K, Nader F, et al. Canadian Indigenous women's perspectives of maternal health and health care services: a systematic review. Divers Equal Health Care 2016;13:334-48.

31. Brown H, Varcoe C, Calam B. The birthing experiences of rural Aboriginal women in context: implications for nursing. Can 7 Nurs Res 2011;43: 100-17.

32. Eni R, Phillips-Beck W, Mehta P. At the edges of embodiment: determinants of breastfeeding for First Nations women. Breastfeed Med 2014;9:203-14.

33. Breastfeeding. Ottawa: Canadian Paediatric Society; updated 2020 August. Available: www.caringforkids.cps.ca/handouts/breastfeeding (accessed 2021 Jan. 6).
34. McClymont E, Fell DB, Albert A, et al. Canadian surveillance of COVID-19 in pregnancy: epidemiology and maternal and infant outcomes. Am 7 Obstet Gynecol 2020;223:969-70.

Affiliations: Department of Family Medicine (Rice), McGill University, Montréal, Que.; Department of Anthropology (Williams), University of Toronto, Toronto, Ont.

Contributors: Kathleen Rice conceived of and designed the study, and obtained the data. Kathleen Rice and Sarah Williams analyzed and interpreted the data, drafted the manuscript and revised the manuscript critically for important intellectual content. Both authors approved the final version to be published and agreed to be accountable for all aspects of the work.

Funding: This study was funded by the Social Sciences and Humanities Research Council of Canada through the Canada Research Chairs Program, and by McGill University research funds.

Content licence: This is an Open Access article distributed in accordance with the terms of the Creative Commons Attribution (CC BY-NC-ND 4.0) licence, which permits use, distribution and reproduction in any medium, provided that the original publication is properly cited, the use is noncommercial (i.e., research or educational use), and no modifications or adaptations are made. See: https://creativecommons.org/licenses/by-nc-nd/4.0/.

Data sharing: All study data are bound by confidentiality agreements and therefore cannot be shared.

Supplemental information: For reviewer comments and the original submission of this manuscript, please see www.cmajopen.ca/content/9/2/ E556/suppl/DC1. 